Check for updates

Cite this: RSC Adv., 2018, 8, 23191

\title{
Surface modification of $\mathrm{CoCr}$ alloys by electrochemical reduction of diazonium salts $\uparrow$
}

\begin{abstract}
M. A. Mezour, ${ }^{a b}$ Y. Oweis, ${ }^{b}$ A. A. El-Hadad, ${ }^{\text {bc }}$ S. Algizani, ${ }^{b}$ F. Tamimi ${ }^{\star b}$ and M. Cerruti ${ }^{\star a}$
Tailoring the surface chemistry of CoCr alloys is of tremendous interest in many biomedical applications. In this work, we show that $\mathrm{CoCr}$ can be modified by diazonium electrografting provided the surface is not homogeneously covered with an oxide layer. Cyclic voltammetry (CV) and X-ray photoelectron spectroscopy (XPS) show the electrografting of a poly(aminophenylene) (PAP) layer on $\mathrm{CoCr}$ when treated at a reductive potential $\left(\mathrm{CoCr}_{-0.5}\right.$ v), whereas no PAP film was formed on $\mathrm{CoCr}_{\mathrm{OCP}}$ and $\mathrm{CoCr}_{1} \mathrm{v}$, treated at open circuit and anodic potentials respectively. Based on XPS results, we attributed the electrografting to the formation of carbide bonds between PAP and the inhomogeneous thin oxide layer

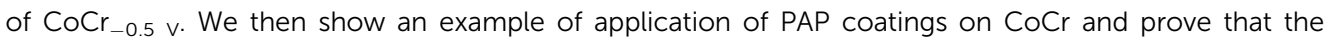
presence of a PAP coating on $\mathrm{CoCr}_{-0.5} \vee$ results in a 5 -fold increase of the adherence of poly methyl methacrylate (PMMA) to PAP-coated CoCr compared to uncoated samples; this is of prime significance to improving the long-term stability of dental prostheses. These findings support the importance of reducing the oxide layer for effective functionalization of metal oxides with aryl diazonium salts and suggest a promising surface modification approach for biomedical applications.
\end{abstract}

Received 27th March 2018 Accepted 5th April 2018

DOI: $10.1039 / \mathrm{c} 8 \mathrm{ra0} 2634 \mathrm{c}$

rsc.li/rsc-advances fact, some studies report that diazonium molecules interact only through weak electrostatic interactions with oxide surfaces, which makes the grafting inefficient. ${ }^{17-19}$ Other authors, instead, report the formation of covalent bond between aryl diazonium and the metal oxide. ${ }^{9,10,20}$ For instance, XPS, Raman and time-of-flight secondary ion mass spectrometry (ToF-SIMS) analysis revealed the existence of both $\mathrm{M}-\mathrm{O}-\mathrm{C}$ (metal-oxide-aryl) and $\mathrm{M}-\mathrm{C}$ (metal-aryl) bonds on $\mathrm{Cu},{ }^{21} \mathrm{Al}^{22}$ and $\mathrm{Mn}^{23}$ oxides, and only $\mathrm{M}-\mathrm{O}-\mathrm{C}$ on $\mathrm{Cr}^{24}$ and Fe oxides. ${ }^{25}$ Other authors reported aryl diazonium grafting onto indium tin oxide (ITO), ${ }^{8}$ fluorine tin oxide (FTO), ${ }^{26}$ and stainless steel, ${ }^{27}$ but did not discuss the type of bonds involved.

In this work, we aim at understanding the nature of the bonds formed between aryl diazonium compounds and oxide surfaces using CoCr as a model metal oxide. CoCr alloys are commonly used in a variety of applications, including wind turbines, ${ }^{28}$ engine components ${ }^{29}$ as well as orthopedic and orthodontic devices, ${ }^{30,31}$ thanks to their high biocompatibility, superior wear and corrosion resistance, and good workability and ductility. These properties are directly related to the spontaneous formation of chromium oxide $\left(\mathrm{Cr}_{2} \mathrm{O}_{3}\right)$ and cobalt oxide (CoO) on the CoCr surface. In dentistry, CoCr alloys are bound to acrylic polymers to manufacture dental devices such as removable partial dentures (RPDs) (2,33 $^{32}$ and resin-bonded partial prostheses. ${ }^{34}$ However, these devices often fail prematurely due to the poor bond between the metal and the polymeric components. ${ }^{35,36}$

Several methods have been used to increase the bond strength between polymers and CoCr alloys, including the 
surface modification of the alloy with silane and phosphate molecules. ${ }^{37-39}$ However, the low stability of these molecular layers in the $\mathrm{pH}$ and temperature conditions experienced in the oral cavity urged us to explore diazonium coating as potential alternative.

Here, we first study how the presence of an oxidation layer on CoCr affects the electrochemical grafting of PAP, and then we show that a thin, cohesive, and covalently bonded PAP film significantly strengthens the adhesion of PMMA to CoCr.

\section{Materials and methods}

\section{Materials}

Cobalt chromium (CoCr alloy super 6) cylinders with a length of $18.71 \mathrm{~mm}$ and a diameter of $7.86 \mathrm{~mm}$ were obtained from Dental Depot (Fort Lauderdale, USA) and were cut into shorter disks (4.57 mm length). PPD (para-phenylenediamine), sodium nitrite $\left(\mathrm{NaNO}_{2}\right)$ and ruthenium hexamine trichloride $\left(\mathrm{Ru}\left(\mathrm{NH}_{3}\right)_{6} \mathrm{Cl}_{3}\right)$ were purchased from Sigma Aldrich (St. Louis, MO). PMMA and MMA were purchased from Great Lakes Orthodontics (Tonawanda, NY). All chemicals were used as received.

\section{Methods}

Surface polishing. The CoCr disks were polished with 2000 and 4000 silicon carbide abrasive paper followed by a fine polishing with Buehler $1 \mu \mathrm{m}, 0.3 \mu \mathrm{m}$, and $0.05 \mu \mathrm{m}$ alumina slurry. After each polishing step, CoCr disks were rinsed with deionized water, sonicated in an ultrasonic bath for $10 \mathrm{~min}$, and dried using $\mathrm{N}_{2}$.

Electrochemical treatment. Electrochemical experiments were carried out using a CHI 760C workstation (CH Instruments Inc, Austin, TX) and a three-electrode cell. An $\mathrm{Ag} / \mathrm{AgCl}$ (saturated $\mathrm{KCl}$ ) electrode was used as a reference, platinum mesh as the counter electrode, and the CoCr cylinders or disks as working electrode. All solutions were deaerated for 15 min with $\mathrm{N}_{2}$ gas prior to electrochemical experiments. Open circuit potential (OCP) was measured for $15 \mathrm{~min}$. The potentiodynamic polarization tests were performed by scanning the potential from $-1 \mathrm{~V}$ to $1.2 \mathrm{~V}$ at $0.01 \mathrm{~V} \mathrm{~s}^{-1}$ in aqueous $\mathrm{HCl}$ solution $(0.5 \mathrm{M})$. Electrochemical pre-treatment of CoCr surface was carried out by applying the potentials of -0.5 and $1 \mathrm{~V}(v s$. $\mathrm{Ag} / \mathrm{AgCl}$ electrode) for 15 minutes; these pre-treatments were compared with $\mathrm{CoCr}$ at OCP. The pre-treatment potentials were selected based on the domains found on the CoCr polarization curves (see Fig. 1 and discussion in the Results section). The oxide reformation was minimized by operating in $\mathrm{O}_{2}$ free solution and by storing samples under $\mathrm{N}_{2}$.

Surface modification by electrochemical reduction of diazonium. The CoCr surface modification with in situ generated diazonium cations was performed in a $0.5 \mathrm{M} \mathrm{HCl}$ solution containing PPD and $\mathrm{NaNO}_{2}$. At first, one equivalent of $\mathrm{NaNO}_{2}(2$ $\mathrm{mM}$ ) was added under stirring to the $0.5 \mathrm{M} \mathrm{HCl}$ electrolytic solution $(20 \mathrm{ml})$ containing PPD $(2 \mathrm{mM})$ at room temperature, and left to react for $5 \mathrm{~min}$. The electrografting was then carried out by repetitive cyclic voltammetry (CV) cycles from $1 \mathrm{~V}$ to $-0.5 \mathrm{~V}$ at $0.05 \mathrm{~V} \mathrm{~s}^{-1}$ and/or by holding the potential at $-0.4 \mathrm{~V}$ for 5 min. The modified CoCr surfaces were then rinsed and sonicated for $5 \mathrm{~min}$ in deionized water. The relative electroactivity of the modified CoCr electrode (PAP-CoCr), which is inversely related to its blocking properties, was quantified by $\mathrm{CV}$ in $5 \mathrm{mM}$ $\mathrm{Ru}\left(\mathrm{NH}_{3}\right)_{6} \mathrm{Cl}_{3} / 0.1 \mathrm{M} \mathrm{KBr}$ at $0.05 \mathrm{~V} \mathrm{~s}^{-1}$.

Tensile bond strength. The strength of the bond achieved between PAP-CoCr disks and PMMA was measured using a tensile test machine (H25K-S, Tinius Olsen Testing Machine Co., Inc Willow Grove, PA) set up at a constant speed of 10 $\mathrm{mm} \min ^{-1}$. The specimens were loaded in the machine as
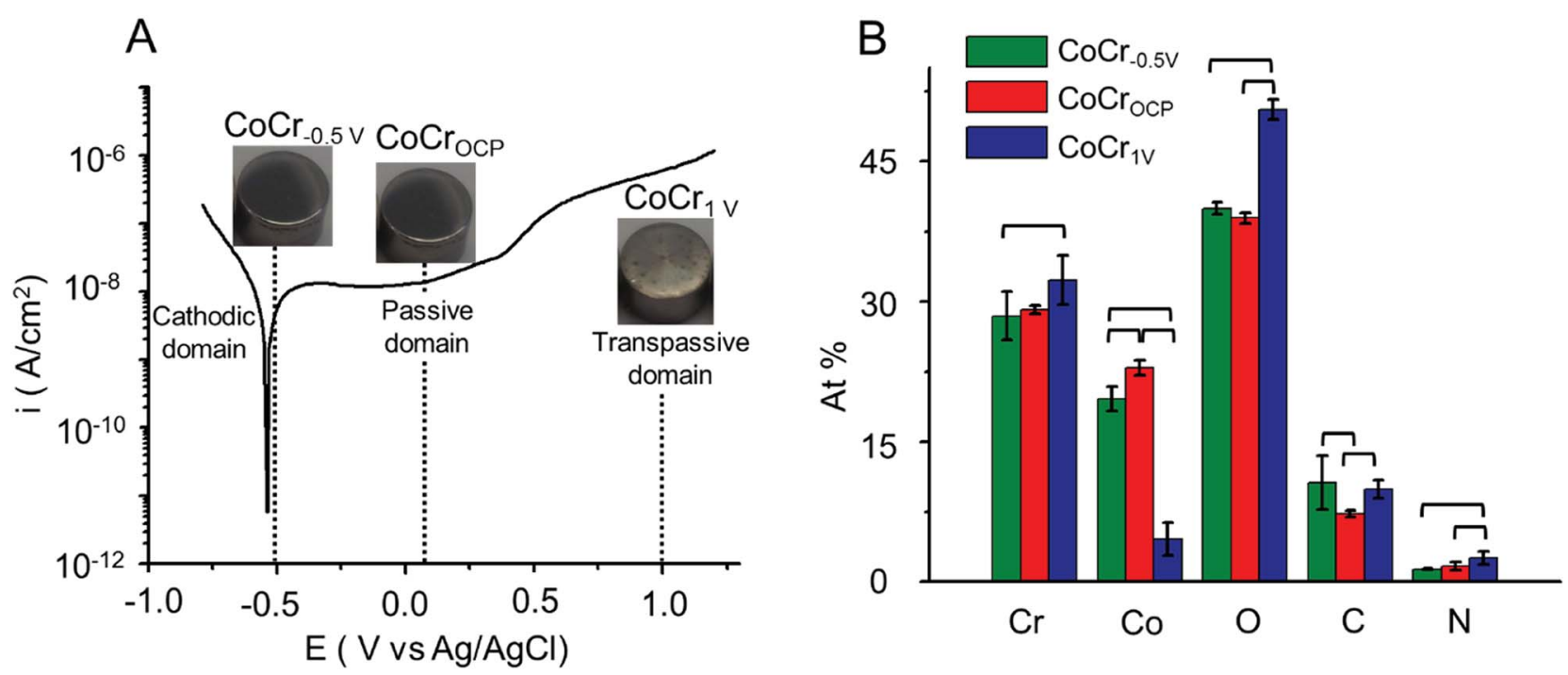

Fig. 1 (A) Potentiodynamic curve of $\mathrm{CoCr}$ alloy in $\mathrm{HCl}(0.5 \mathrm{M})$. The pictures show the visual appearance of $\mathrm{CoCr}_{-0.5 \mathrm{~V}}$, CoCrocp and $\mathrm{CoCr} \mathrm{V}_{1} \mathrm{~V}$ substrates. These samples were obtained by treatment of $\mathrm{CoCr}$ at the potentials of $-0.5 \mathrm{~V}, \mathrm{OCP}$ and $1 \mathrm{~V}$, respectively, selected from the cathodic, passive and transpassive domains. (B) Elemental composition of $\mathrm{CoCr}_{-0.5}$ v, $\mathrm{CoCr}_{\mathrm{OCP}}$ and $\mathrm{CoCr}_{1} \vee$ deduced from XPS survey scans. Brackets indicate statistically significant difference between two groups $(p<0.05)$. 
shown in Fig. 5A. The upper and lower jaws held PMMA and CoCr respectively. To prepare the specimens, the $\mathrm{PAP}-\mathrm{CoCr}$ disks were placed in a custom mold prepared from silicone (Exaktosil N 21, Bredent, Germany). PMMA (Biocryl Resin Acrylic, Great Lakes, NY) powder was mixed to MMA liquid monomer with a ratio of $2: 1$ to make a viscous solution that was poured around the PAP-CoCr disks in the mold and was left to set for $3 \mathrm{~h}$ at room temperature. The resulting PMMA-PAPCoCr specimens were cylindrical in shape and measured $37 \mathrm{~mm}$ long and $7.86 \mathrm{~mm}$ in diameter. PAP free CoCr discs, referred as PMMA-CoCr, served as control.

X-ray photoelectron spectroscopy (XPS). XPS spectra were recorded using ThermoFisher Scientific K-alpha instrument equipped with a monochromatic $\mathrm{Al} \mathrm{K} \alpha$ X-ray source $(1486.6 \mathrm{eV})$. Survey scans and high-resolution scans were collected with an X-ray spot size of $200 \mu \mathrm{m}$ and energy steps of 1 and $0.1 \mathrm{eV}$, respectively. Spectral energies were calibrated by setting the C-C binding energy of $\mathrm{C}_{1 \mathrm{~s}}$ at $284.8 \mathrm{eV}$. Peak fitting was performed using the Thermo Avantage software (version 4.60). The evaluation procedure for peak fitting included Gaussian-Voigt curves functions and an iterated Shirley procedure for background subtraction. For consistency, a similar peak fitting procedure was applied on all samples (Table S1†)..$^{37,40}$

Atomic force microscopy (AFM). AFM was used to examine the changes in surface roughness induced by different treatments of the CoCr surfaces. The AFM experiments were performed at ambient conditions on AFM instrument: a Nanoscope Multimode 8 equipped with a Nanoscope V controller (Bruker, Santa Barbara, CA). The topographies were acquired in ScanAsyst mode and Nanoscope 8.15r3 software. In ScanAsyst mode, silicon nitride cantilevers (ScanAsyst-Air Bruker) with a nominal spring constant of $0.4 \mathrm{~N} \mathrm{~m}^{-1}$, a nominal resonance frequency of $50-90 \mathrm{kHz}$, and a nominal tip radius of $2 \mathrm{~nm}$ were used for imaging in air. AFM image analysis was performed using WSxM, 69 Nanoscope Analysis 1.4 software.

Scanning electron microscopy (SEM). The morphologies and elemental composition of the CoCr surfaces were examined using an Inspect-50 field emission scanning electron microscope (SEM) (FEI, Japan), at $10 \mathrm{kV}$ operating voltage., equipped with an EDX unit.

Statistical analysis. All results were expressed as mean \pm standard deviation (SD) of at least three samples. Statistical analyses were performed on SPSS software (version 22; SPSS Inc, IBM corporation, Chicago IL). Changes $(\Delta)$ in the quantitative data were calculated by comparing pre-treatment and post-treatment measurements. All quantitative data were tested for normality using the Shapiro-Wilk test. For parametric data, a paired-sample $t$-test was used for changes within the same sample, and one-way ANOVA for comparison between more than two groups followed by Tukey HSD test to assess statistical differences. Whereas, Wilcoxon and MannWhitney (for comparison between two groups) and KruskalWallis test (for comparison between more than two groups) were used for non-parametric data. The significance level was set at $p<0.05$.

\section{Results and discussion}

To understand the nature of the bond formed between aryl diazonium layer and CoCr alloy, we started by testing different electrochemical pre-treatments aimed at controlling the thickness of the oxide layer present on the CoCr surface.

\section{Electrochemical pre-treatment of CoCr surface}

A nanometer-thick oxide film grows typically on CoCr upon exposure to oxygen or water at ambient condition. ${ }^{37}$ This is evidenced by an open circuit potential (OCP) of $0.05 \mathrm{~V}$. The OCP shifts towards more anodic potentials (Fig. S1 $\dagger$ ) with time indicating an increase in oxide thickness. ${ }^{9}$

Potentiodynamic polarization provides a good qualitative understanding of the oxidation and reduction processes occurring on the CoCr passive film. Fig. 1A represents a typical potentiodynamic curve of CoCr alloy recorded by scanning the potential from $-1 \mathrm{~V}$ to $1.2 \mathrm{~V}$ at $0.01 \mathrm{~V} \mathrm{~s}^{-1}$ in aqueous $\mathrm{HCl}$ solution $(0.5 \mathrm{M})$.

The polarization curve can be divided into three different zones. ${ }^{37}$ The cathodic zone $(E<-0.55 \mathrm{~V})$ is characterized by a negative current mainly dominated by the reduction of water and hydrogen evolution. In the passive zone $(-0.3$ to $0.6 \mathrm{~V})$, the current remained relatively constant while the thickness of the passivating film grew proportionally with the potential. Finally, in the transpassive zone $(E>0.6 \mathrm{~V})$ a marked increase of current is observed and associated with the dissolution of the oxide layer as well as water oxidation. ${ }^{38}$

Based on the polarization curve, we selected two potentials in the active and transpassive domains, i.e. $-0.5 \mathrm{~V}$ and $1 \mathrm{~V}$, respectively, and we applied each potential on the CoCr disks for 15 min (samples labelled $\mathrm{CoCr}_{-0.5 \mathrm{v}}$ and $\mathrm{CoCr}_{1} \mathrm{v}$, respectively). We used CoCr at OCP, which is located in the passive domain of CoCr, as control (sample labelled $\mathrm{CoCr}_{\mathrm{OCP}}$ ). The visual appearance of the discs after this treatment is shown in the pictures reported in Fig. 1. While $\mathrm{CoCr}_{-0.5} \mathrm{v}$ and $\mathrm{CoCr}_{\mathrm{OCP}}$ showed a smooth and mirror shiny surface similar to CoCr surface before the treatment (Fig. $\mathrm{S} 2 \dagger$ ), $\mathrm{CoCr}_{1}$ v showed a rough and brighter appearance, indicative of accelerated surface corrosion.

We assessed the elemental composition of $\mathrm{CoCr}_{-0.5} \mathrm{~V}$, $\mathrm{CoCr}_{1 \mathrm{v}}$, and $\mathrm{CoCr}_{\mathrm{OCP}}$ using XPS (Fig. 1B). All samples contained $\mathrm{Co}, \mathrm{Cr}, \mathrm{O}$ and $\mathrm{C}$ atoms, in addition to a small amount of $\mathrm{N}$ $(<2.5 \%)$, possibly added during the casting process to improve the mechanical properties of CoCr alloy. ${ }^{39} \mathrm{CoCr}_{-0.5} \mathrm{v}$ and $\mathrm{CoCr}_{\mathrm{OCP}}$ showed similar amounts of $\mathrm{Cr}$ and Co, with just approximately $7 \%$ more $\mathrm{Cr}$ than Co on average. In contrast, the surface layer on $\mathrm{CoCr}_{1} \mathrm{v}$ contained mainly $\mathrm{Cr}(32 \pm 3 \%)$ and a lower amount of Co $(5 \pm 2 \%)$. This can be explained by the increasing thickness of the Cr rich oxide layer and the preferential dissolution of Co atoms in the transpassive domain. ${ }^{37}$ The concentration of $\mathrm{O}$ significantly increased going from $\mathrm{CoCr}_{-0.5} \mathrm{~V}$ to $\mathrm{CoCr}_{1} \mathrm{v}$, indicating a proportional growth of oxide layer at anodic potential. Less $\mathrm{C}(7 \pm 1 \%)$ is present on $\mathrm{CoCr}_{\mathrm{OCP}}$ compared to $\mathrm{CoCr}_{-0.5 \mathrm{v}}(10 \pm 1 \%)$ and $\mathrm{CoCr}_{1 \mathrm{v}}(11 \pm 3 \%)$. This might originate from the carbon component of the CoCr alloy and adventitious carbon-based contaminants. 

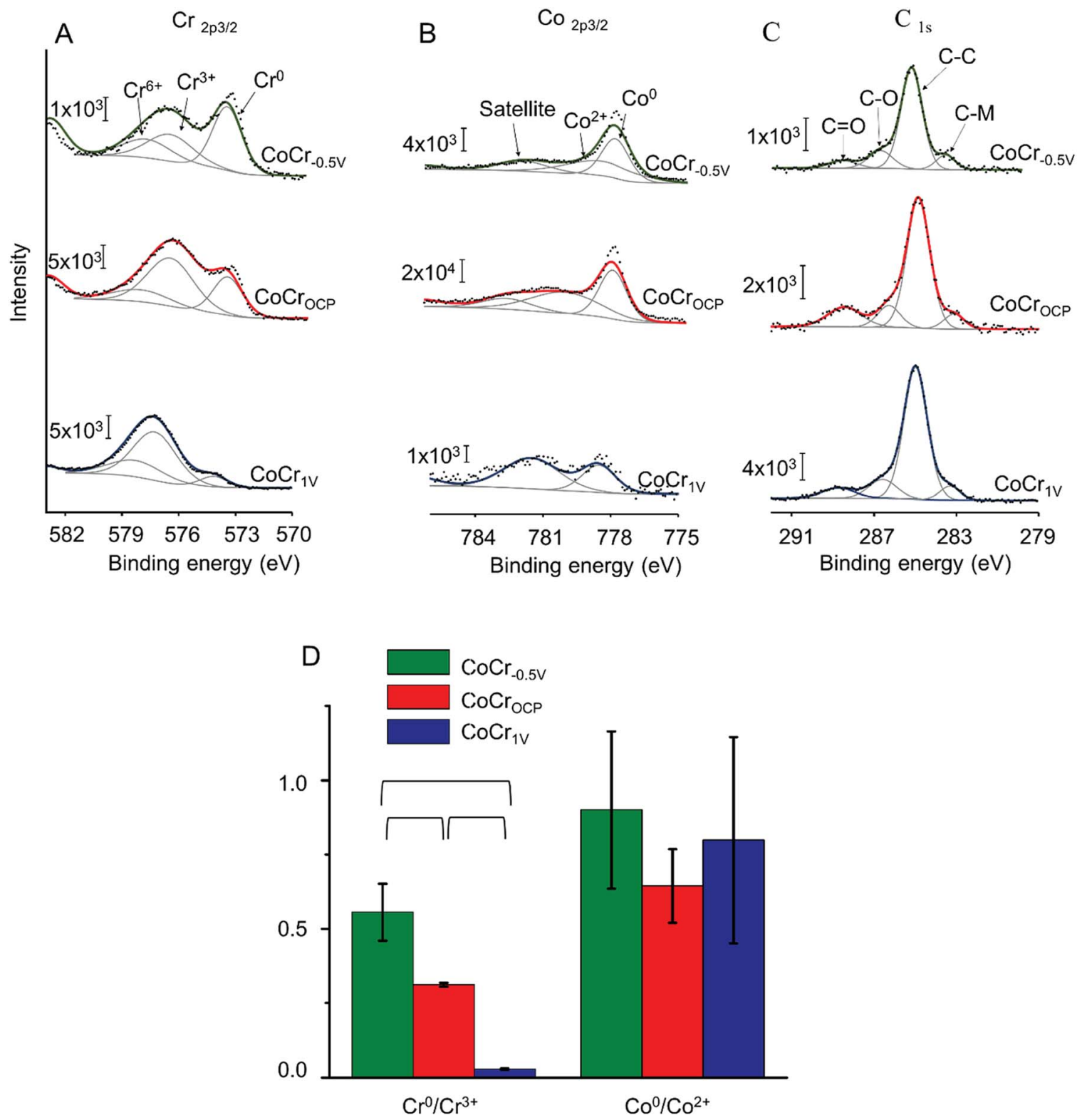

Fig. 2 Representative high resolution (A) $\mathrm{Cr}_{2 \mathrm{p}_{3 / 2^{\prime}}}$ (B) $\mathrm{CO}_{2 \mathrm{p}_{3 / 2}}$ and (C) $\mathrm{C}_{1 \mathrm{~s}} \mathrm{XPS}$ spectra recorded on $\mathrm{CoCr}_{-0.5 \mathrm{~V}}, \mathrm{CoCr}_{\mathrm{OCP}}$, and $\mathrm{CoCr}_{1} \mathrm{v}$. Cr $2 \mathrm{p}_{1 / 2}$ and $\mathrm{CO}_{2 \mathrm{p}_{1 / 2}}$ peaks were omitted for clarity. In all panels $(\mathrm{A}-\mathrm{C})$, experimental data are shown in black, peak fits in gray and the overall fit in green $\left(\mathrm{CoCr}_{1} \mathrm{v}\right)$, red $\left(\mathrm{CoCr}_{\mathrm{OCP}}\right)$, or blue $\left(\mathrm{CoCr}_{-0.5} \mathrm{v}\right)$. (D) Ratio of the areas of the $\mathrm{Cr}^{0} / \mathrm{Cr}^{3+}$ and $\mathrm{Co}^{0} / \mathrm{Co}^{2+}$ components measured on the high-resolution spectra of $\mathrm{Cr}$ and $\mathrm{Co}$ for $\mathrm{CoCr}_{-0.5}$ v, CoCrocp and $\mathrm{CoCr}_{1} \mathrm{v}$. Brackets indicate statistically significant differences between two groups ( $\left.p<0.05\right)$.

To explore further the chemical environment of surface atoms, we recorded high resolution $\mathrm{Cr}_{2 \mathrm{p}}, \mathrm{Co}_{2 \mathrm{p}}$, and $\mathrm{C}_{1 \mathrm{~s}}$ spectra (Fig. 2 and Table $\mathrm{S} 1 \dagger$ ). On all samples, the $\mathrm{Cr}_{2 \mathrm{p}_{3 / 2}}$ and $\mathrm{Co}_{2 \mathrm{p}_{3 / 2}}$ peaks showed a metallic component at low binding energy and a broader envelope of peaks attributed to multiplet splitting of the oxides and hydroxides peaks. ${ }^{41}$ In this study, the $\mathrm{Cr}_{2 \mathrm{p}_{3 / 2}}$ spectra was fitted with a single peak at approximately $573.8 \mathrm{eV}$ attributed to $\mathrm{Cr}^{0}$ and two oxidized components at approximately $577 \mathrm{eV}$ and $578.6 \mathrm{eV}$ relative to $\mathrm{Cr}^{3+}$ and $\mathrm{Cr}^{6+}$ respectively. The $\mathrm{Co}_{2 \mathrm{p}_{3 / 2}}$ envelope was deconvoluted with a metallic $\mathrm{Co}^{0}$ peak at approximately $778 \mathrm{eV}$, an oxidized component at approximately $779.5 \mathrm{eV}$ corresponding to $\mathrm{Co}^{2+}$, and a satellite peak at approximately $782 \mathrm{eV}$ related to $\mathrm{Co}^{2+}{ }^{21}$ The carbon peak can be deconvoluted with four components: a low binding energy peak at $283 \mathrm{eV}$ assigned to carbide bonds (C-M), ${ }^{12}$ possibly due to the inter-dendritic precipitation of carbon during $\mathrm{CoCr}$ fabrication, ${ }^{42}$ a peak at $284.8 \mathrm{eV}$ related to $\mathrm{sp}^{3}$ carbon $(\mathrm{C}-\mathrm{C})$, and two peaks at higher binding energies $(285 \mathrm{eV}$ and $288 \mathrm{eV})$ attributed to $\mathrm{C}-\mathrm{O}$ and $\mathrm{C}=\mathrm{O}$ bonds respectively ${ }^{43}$ The latter three peaks are likely due to adventitious carbon-based contaminants usually found on surfaces exposed to atmosphere. ${ }^{25}$

The $\mathrm{Cr}^{0} / \mathrm{Cr}^{3+}$ ratio decreased significantly from $0.6 \pm 0.1$ for $\mathrm{CoCr}_{-0.5 \mathrm{v}}$ to $0.3 \pm 0.05$, and to $0.03 \pm 0.01$ for $\mathrm{CoCr}_{\mathrm{OCP}}$ and $\mathrm{CoCr}_{1 \mathrm{~V}}$ respectively (Fig. 2D). The high $\mathrm{Cr}^{0} / \mathrm{Cr}^{3+}$ ratio observed on $\mathrm{CoCr}_{-0.5 \mathrm{v}}$ might be explained by the partial elimination of the chromium rich oxide layer that generally forms at ambient 
conditions (i.e. at OCP). Vice versa, anodic potentials accelerate the growth of the oxide layer, thus decreasing the $\mathrm{Cr}^{0} / \mathrm{Cr}^{3+}$ ratio. Differently from $\mathrm{Cr}$, Co showed a higher $\mathrm{Co}^{0} / \mathrm{Co}^{2+}$ ratio that does not change significantly with surface treatment. This can be attributed to the lower susceptibility to oxidation of Co relative to $\mathrm{Cr}$.

Overall, these results indicate that an oxide layer is formed on $\mathrm{CoCr}$ when treated at anodic potentials. On $\mathrm{CoCr}_{\mathrm{OCP}}$ the oxide film is composed of a mixture of both $\mathrm{Co}$ and $\mathrm{Cr}$, whereas on $\mathrm{CoCr}_{1 \mathrm{v}}$, it is mainly dominated by chromium oxides. On the contrary, the oxide layer is partially dissolved on CoCr treated at cathodic potential, i.e. $\mathrm{CoCr}_{-0.5} \mathrm{v}$.

\section{PAP binding as a function of the CoCr surface electrochemical pretreatment}

The efficacy of PAP binding on the pretreated CoCr samples can be compared by performing cyclic voltammetry (CV) on these substrates in the presence of PPD and $\mathrm{NaNO}_{2}$ (Fig. 3A).

The first cycle of the $\mathrm{CV}$ recorded for PAP binding on $\mathrm{CoCr}_{-0.5 \mathrm{~V}}$ (Fig. 3A, first row) showed a broad irreversible peak at $-0.05 \pm 0.1 \mathrm{~V}$. In the subsequent CV scans, the current of this reductive peak is drastically diminished and vanishes in the fifth cycle, indicating the passivation of the $\mathrm{CoCr}_{-0.5 \mathrm{v}}$ electrode by an electrically insulating layer of PAP molecules. This CV behavior is characteristic of a covalent bonding between the in situ generated diazonium radical and the CoCr surface. ${ }^{44-46}$ No oxidative peak was found in the $\mathrm{CV}$, indicating no polyaniline
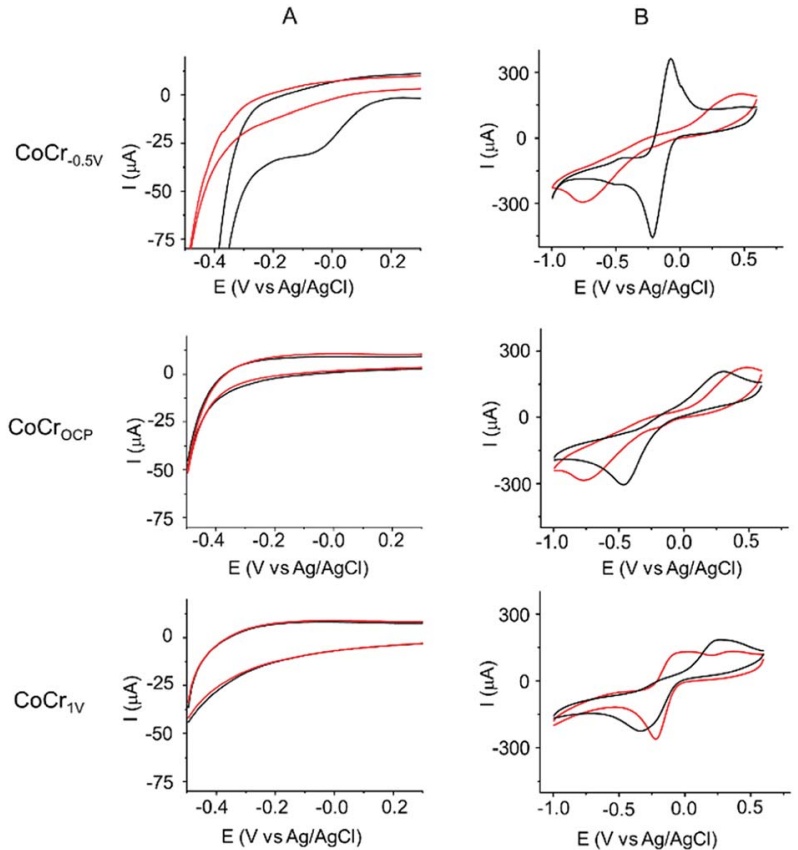

Fig. 3 CVs measured on $\mathrm{CoCr}_{-0.5 \vee}$ (first row), $\mathrm{CoCr}_{\mathrm{OCP}}$ (second row) and $\mathrm{CoCr}_{1} \vee$ (third row) during and after PAP grafting. (A) CVs performed in de-aerated $0.5 \mathrm{M} \mathrm{HCl}$ containing $2 \mathrm{mM}$ of PPD and 1 equivalent of $\mathrm{NaNO}_{2}$. The black and red lines indicate the first and fifth cycles, respectively. (B) CVs performed in aqueous solution of $5 \mathrm{mM}$ $\mathrm{Ru}\left(\mathrm{NH}_{3}\right)_{6} \mathrm{Cl}_{3} / 0.1 \mathrm{M} \mathrm{KBr}$ before (black) and after (red) electrochemical binding of PAP. Scan rate was $50 \mathrm{mV} \mathrm{s}^{-1}$. formation. The control experiments of PAP binding on glassy carbon and gold electrodes showed similar CV behaviour with an irreversible reduction wave at $-0.3 \mathrm{~V}$ and $-0.25 \mathrm{~V}$ respectively (Fig. S3 $\uparrow$ ). On the other hand, $\mathrm{CoCr}_{\mathrm{OCP}}$ and $\mathrm{CoCr}_{1 \mathrm{v}}$ show a featureless CV suggesting the failure of PAP binding (Fig. 3A, second and third row).

We tested this hypothesis by investigating the blocking properties toward the $\mathrm{Ru}\left(\mathrm{NH}_{3}\right)_{6}{ }^{3+/ 2+}$ redox couple of the substrates before and after PAP binding (Fig. 3B). The presence of a PAP layer is expected to slow the voltammetric response, causing an increase in the separation between the anodic and cathodic peak potential $\left(\Delta E_{\mathrm{p}}\right)$ and a decrease in the intensity of the cathodic and anodic currents.

Even before electrochemical reduction of PAP (red lines in Fig. 3B), the three surfaces showed different barrier properties toward $\mathrm{Ru}\left(\mathrm{NH}_{3}\right)_{6}{ }^{3+/ 2+}$. $\mathrm{CoCr}_{\mathrm{OCP}}$ (Fig. 3B, second row) revealed a large $\Delta E_{\mathrm{p}}(>0.9 \mathrm{~V})$ confirming the presence of a passivating oxide layer on $\mathrm{CoCr}$ at OCP. This value is much higher than that measured on $\mathrm{CoCr}_{-0.5} \mathrm{v}\left(0.14 \mathrm{~V}\right.$, Fig. 3B, first row) and $\mathrm{CoCr}_{1} \mathrm{v}$ (0.6 V, Fig. 3B, third row). The lower barrier towards $\mathrm{Ru}\left(\mathrm{NH}_{3}\right)_{6}{ }^{3+/ 2+}$ redox reaction shown by $\mathrm{CoCr}_{-0.5 \mathrm{v}}$ agrees well with the thinner oxide layer observed at cathodic potentials by XPS, while on $\mathrm{CoCr}_{1}$ v the inhomogeneous texture of the transpassive oxide might explain the low resistivity of the surface. ${ }^{47}$

After PAP binding (black lines in Fig. 3B), no big changes are visible on the CVs measured on $\mathrm{CoCr}_{\mathrm{OCP}}$ and $\mathrm{CoCr}_{1 \mathrm{v}}$ (Fig. 3B). This result confirms that PAP binding was inhibited on the oxidized surfaces of $\mathrm{CoCr}_{\mathrm{OCP}}$ and $\mathrm{CoCr}_{1 \mathrm{v}}$. On the contrary, the PAP film grown on $\mathrm{CoCr}_{-0.5} \mathrm{v}$ strongly blocks the redox reactions of $\mathrm{Ru}\left(\mathrm{NH}_{3}\right)_{6}{ }^{3+/ 2+}$, as shown by the marked increase in $\Delta E_{\mathrm{p}}$ and the significant attenuation of the cathodic and anodic currents (Fig. 3B). The PAP layer formed on $\mathrm{CoCr}_{-0.5} \mathrm{v}$ is inhomogeneous (Fig. S5 $\dagger$ ) and a few nanometer thick, causing an increase in RMS roughness from $1.7 \mathrm{~nm}$ before coating to $6 \mathrm{~nm}$ after coating (Fig. S6†).

We further assessed PAP formation on the substrates by performing XPS on the PAP coated samples (Fig. 4). As for the uncoated $\mathrm{CoCr}$ substrates, the survey scans showed the presence of $\mathrm{Cr}$, Co, O, C and $\mathrm{N}$ on all samples (Fig. S4 $\dagger$ ).

After PAP binding, we observed a significant increase in $\mathrm{C}$ accompanied with a decrease of $\mathrm{Co}$ and $\mathrm{Cr}$. The O content remained almost constant and $\mathrm{N}$ increased slightly after electrografting on $\mathrm{CoCr}_{-0.5} \mathrm{v}$ and $\mathrm{CoCr}_{\mathrm{OCP}}$ (Fig. 4A). This result indicates the presence of a carbon based organic coating at all CoCr surfaces (regardless of the nature of the oxide layer). The coating might be attributed to PAP film formation, but also to adventitious carbon-based contamination, since electrochemistry did not show evidence of electrografting taking place on $\mathrm{CoCr}_{\mathrm{OCP}}$ and $\mathrm{CoCr}_{1 \mathrm{v}}$ (Fig. 3).

To further assess the nature of this organic coating, we analysed the high resolution $\mathrm{C}_{1 \mathrm{~s}}$ spectra of the three $\mathrm{CoCr}$ substrates (Fig. 4B). The $\mathrm{C}-\mathrm{C}$ and $\mathrm{C}-\mathrm{O}$ components increased significantly on all surfaces and are higher on the $\mathrm{CoCr}_{-0.5} \mathrm{v}$ than on others; no significant differences among surfaces are detected for the $\mathrm{C}-\mathrm{O}$ component, and less $\mathrm{C}=\mathrm{O}$ is found on $\mathrm{CoCr}_{-0.5 \mathrm{v}}$ than on the other surfaces (Fig. 4C). However, again, these components may originate from both PAP layer formation 
A
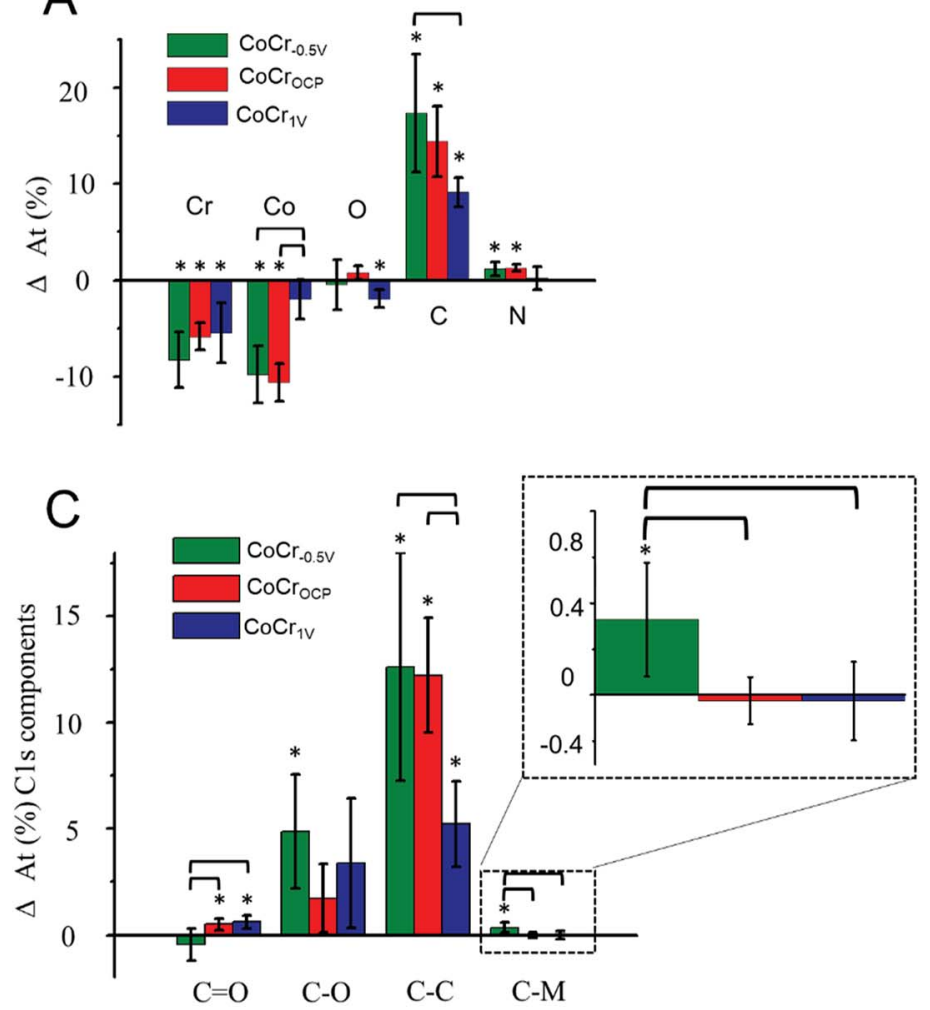
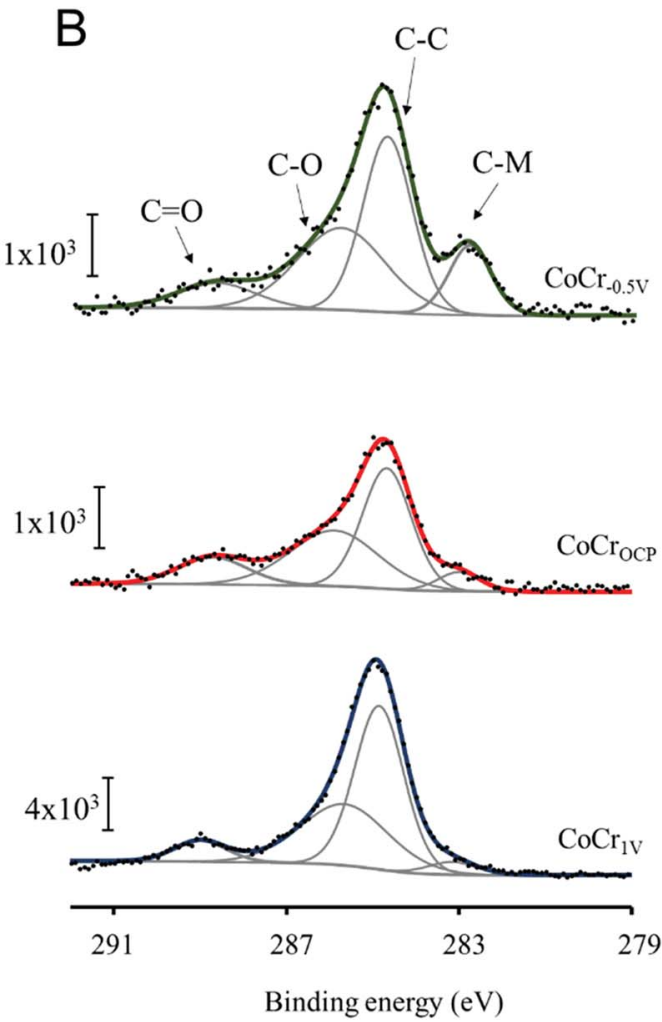

Fig. 4 PAP electrografting on $\mathrm{CoCr}_{-0.5}$ v, CoCrocP, and $\mathrm{CoCr}_{1}$ v analyzed by XPS. (A) Differences in elemental composition measured by XPS survey scans before and after electrografting. (B) Representative high resolution $C_{1 s}$ XPS spectra recorded after PAP electrografting. (C) Differences in relative intensities of the components used to deconvolute $C_{1 s}$ spectra measured on samples before and after PAP electrografting. Asterisk signs indicate a significant change within the same sample group following PAP treatment $(p<0.05)$. Brackets indicate statistically significant differences between two groups $(p<0.05)$.

and adventitious contaminants that are hardly avoidable during XPS analysis. The C-M component instead can only originate from the covalent binding between PAP and CoCr. Due to the complex alloy surface composition, we were unable to determine the exact nature of the carbide bond. However, we hypothesize that PAP forms a bond with $\mathrm{Cr}$, since this element is predominantly present on the surface of $\mathrm{CoCr}_{-0.5} \mathrm{v}$ (Fig. 2).

The $\mathrm{C}-\mathrm{M}$ component was previously reported to be a direct proof for the existence of a covalent bond between the aryl group and different substrates (i.e. iron $^{48}$ and stainless stee ${ }^{49}$ ).

After electrografting, this component increased significantly on $\mathrm{CoCr}_{-0.5 \mathrm{v}}$ compared to $\mathrm{CoCr}_{\mathrm{OCP}}$ and $\mathrm{CoCr}_{1 \mathrm{v}}$. This result indicates that a covalent bond forms only between PAP and the surface of $\mathrm{CoCr}_{-0.5} \mathrm{v}$, which is covered with a thin and inhomogeneous oxide layer. The high resolution $\mathrm{N}_{1 \mathrm{~s}}$ spectra of $\mathrm{CoCr}_{-0.5} \mathrm{v}$ show a significant increase in the amine peak at $400 \mathrm{eV}$ and decrease of the metal nitride peak at $394 \mathrm{eV}$ after grafting compared to the pristine surface (Fig. S7†). These changes further confirm the presence of a PAP layer on this sample.

This result correlates well with previous studies on aryl diazonium grafting on oxide-free metals such as $\mathrm{Au}^{12}$ and $\mathrm{Cu}^{21}$ From the XPS and electrochemistry data we can conclude that the electrografting occurs on $\mathrm{CoCr}$ when its oxide is reduced.

\section{Efficacy of PAP layer in promoting binding of PMMA to $\mathrm{CoCr}$}

We tested the ability of the electrografted PAP layer to improve the adhesion of PMMA to CoCr by simply adding PMMA to the PAP-treated $\mathrm{CoCr}$ surfaces and measuring the tensile bond strength at the PMMA-CoCr interface (Fig. 5A). Our hypothesis was that the branched structure of the PAP layer could be exploited to promote PMMA binding through polymeric chain entanglement and hydrogen bonding.

While there were no significant differences between the bond strength measured between PMMA and bare CoCr $(0.9 \pm$ 0.6 MPa) vs. PMMA and PAP-treated $\mathrm{CoCr}_{\mathrm{OCP}}(1.4 \pm 1.0 \mathrm{MPa})$, the tensile bond strength measured on PAP-treated $\mathrm{CoCr}_{-0.5 \mathrm{~V}}$ was almost five times higher $(5.1 \pm 1.2 \mathrm{MPa})$ (Fig. 5B). This result confirms that the presence of a PAP layer on $\mathrm{CoCr}_{-0.5 \mathrm{~V}}$ significantly increases the bond strength between PMMA and CoCr, likely due to chain entanglement and hydrogen bonds that form between the amine groups of PAP and the carbonyls of PMMA. The lack of significant differences between untreated $\mathrm{CoCr}$ and PAP-treated $\mathrm{CoCr}_{\mathrm{OCP}}$ confirms the failure of PAP coating in the presence of an oxide layer on CoCr.

Several adhesives are reported in the literature to bind PMMA to metals, namely those based on silane and phosphonate molecules. ${ }^{37-39}$ However, due to differences in test methodology and the fact that the reported coupling agents required 

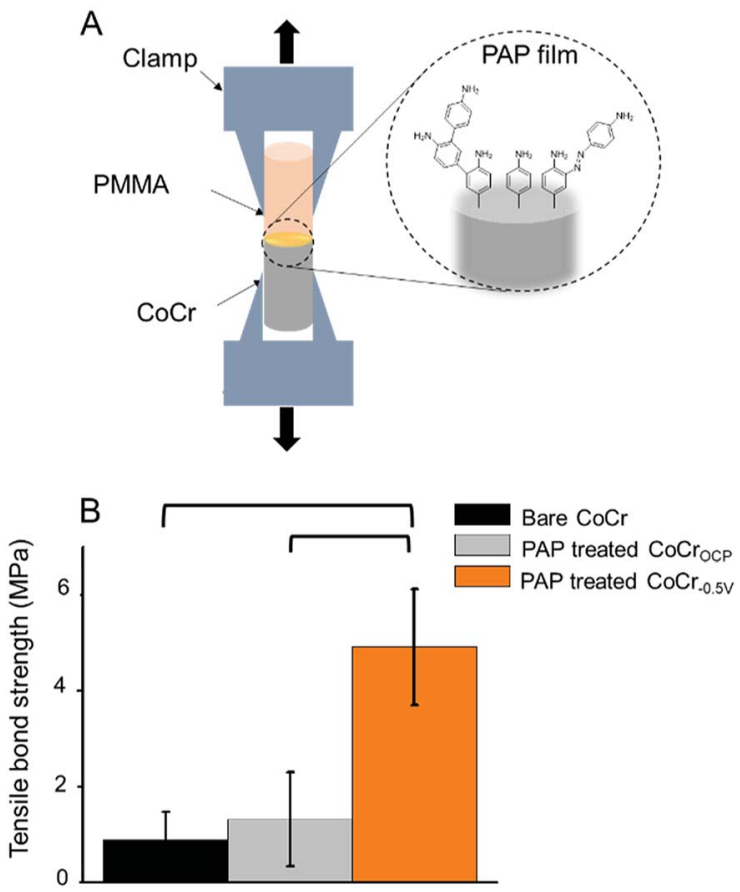

Fig. 5 (A) Schematic of the mechanical test designed to measure the interfacial bond strength between different $\mathrm{CoCr}$ samples and PMMA (B) Tensile bond strength between PMMA and bare CoCr (black), PAPtreated $\mathrm{CoCr}_{\mathrm{OCP}}$ (grey) and PAP-treated $\mathrm{CoCr}_{-0.5 \mathrm{v}}$ (orange). Brackets indicate statistically significant differences between groups $(p<0.05)$

some type of surface pretreatment such as sandblasting, ${ }^{44,50}$ silica coating, ${ }^{51}$ and alloy priming, ${ }^{52,53}$ a straightforward comparison between these adhesives and diazonium chemistry is not possible. Instead, the difference between the control and treated groups could be used as an indication of the efficiency of diazonium treatment: in fact, the five fold improvement in tensile bond strength obtained with diazonium is comparable ${ }^{54}$ than most of the values reported in literature for silane and phosphonates based adhesives, which range between 1.5 and 5 fold.

\section{Conclusions}

We show that the efficacy of electrografting PAP on CoCr is closely related to the composition of the CoCr surface. The presence of a passivating oxide layer on $\mathrm{CoCr}$ at OCP or when electrochemically treated at anodic potentials hinders PAP electrografting. In contrast, reducing the oxide thickness by treating $\mathrm{CoCr}$ at cathodic potentials favors PAP electrografting through the formation of metal carbide bonds. The presence of a PAP coating on $\mathrm{CoCr}_{-0.5 \mathrm{~V}}$ results in a 5 -fold increase in bond strength between PMMA and CoCr compared to uncoated CoCr samples. Thus, aryl diazonium coating offers a strong and stable alternative to the commonly used silane and phosphonate adhesives: in addition to the comparable or higher increase in strength measured in this work, the bonds formed by diazonium are much more stable in aqueous environments and large $\mathrm{pH}$ intervals thanks to the remarkable resistance of $\mathrm{C}-\mathrm{M}$ bond to hydrolysis. ${ }^{46,55}$

\section{Conflicts of interest}

There are no conflicts of interest to declare.

\section{Acknowledgements}

We acknowledge Natural Sciences and Engineering Research Council (NSERC) of Canada, the Fonds de recherche du Québec - Nature et technologies (FRQNT), the Canada Research Chair foundation (CRC), and the Center of Self-Assembled Chemical Structures. M. A acknowledge the Network for Oral and Bone Health Research (RSBO) and 3DRPDMD for their financial support. Help extended by Dr Bruce Lennox, Dr Sasha Omanovic and Dr Mario Ascencio Pinedo in electrochemical experiments is also acknowledged.

\section{Notes and references}

1 M. Delamar, R. Hitmi, J. Pinson and J. M. Saveant, J. Am. Chem. Soc., 1992, 114, 5883-5884.

2 A. Chaussé, M. M. Chehimi, N. Karsi, J. Pinson, F. Podvorica and C. Vautrin-Ul, Chem. Mater., 2002, 14, 392-400.

3 C. Cao, Y. Zhang, C. Jiang, M. Qi and G. Liu, ACS Appl. Mater. Interfaces, 2017, 9, 5031-5049.

4 S. Mahouche-Chergui, S. Gam-Derouich, C. Mangeney and M. M. Chehimi, Chem. Soc. Rev., 2011, 40, 4143-4166.

5 H. Mahjoubi, J. M. Kinsella, M. Murshed and M. Cerruti, ACS Appl. Mater. Interfaces, 2014, 6, 9975-9987.

6 O. Alageel, M. N. Abdallah, Z. Y. Luo, J. Del-Rio-Highsmith, M. Cerruti and F. Tamimi, Dent. Mater., 2015, 31, 105-114.

7 X. T. Le, N. D. Doan, T. Dequivre, P. Viel and S. Palacin, ACS Appl. Mater. Interfaces, 2014, 6, 9085-9092.

8 S. Maldonado, T. J. Smith, R. D. Williams, S. Morin, E. Barton and K. J. Stevenson, Langmuir, 2006, 22, 2884-2891.

9 P. Allongue, M. Delamar, B. Desbat, O. Fagebaume, R. Hitmi, J. Pinson and J.-M. Savéant, J. Am. Chem. Soc., 1997, 119, 201207.

10 J. Pinson and F. Podvorica, Chem. Soc. Rev., 2005, 34, 429439.

11 T. Itoh and R. L. McCreery, J. Am. Chem. Soc., 2002, 124, 10894-10902.

12 L. Laurentius, S. R. Stoyanov, S. Gusarov, A. Kovalenko, R. Du, G. P. Lopinski and M. T. McDermott, ACS Nano, 2011, 5, 4219-4227.

13 J. M. Hicks, Z. Y. Wong, D. J. Scurr, N. Silman, S. K. Jackson, P. M. Mendes, J. W. Aylott and F. J. Rawson, Langmuir, 2017, 33, 4924-4933.

14 V. Rebuttini, E. Fazio, S. Santangelo, F. Neri, G. Caputo, C. Martin, T. Brousse, F. Favier and N. Pinna, Chemical Modification of Graphene Oxide through Diazonium Chemistry and Its Influence on the Structure-Property Relationships of Graphene Oxide-Iron Oxide Nanocomposites, Chem.-Eur. J., 2015, 21, 12465-12474.

15 M. G. Paulik, P. A. Brooksby, A. D. Abell and A. J. Downard, J. Phys. Chem. C, 2007, 111, 7808-7815.

16 A. Jacques, S. Devillers, J. Delhalle and Z. Mekhalif, Electrochim. Acta, 2013, 109, 781-789. 
17 H. Ma, L. Lee, P. A. Brooksby, S. A. Brown, S. J. Fraser, K. C. Gordon, Y. R. Leroux, P. Hapiot and A. J. Downard, J. Phys. Chem. C, 2014, 118, 5820-5826.

18 B. Cui, J.-Y. Gu, T. Chen, H.-J. Yan, D. Wang and L.-J. Wan, Langmuir, 2013, 29, 2955-2960.

19 D. R. Jayasundara, R. J. Cullen and P. E. Colavita, Chem. Mater., 2013, 25, 1144-1152.

20 D. Belanger and J. Pinson, Chem. Soc. Rev., 2011, 40, 39954048.

21 B. L. Hurley and R. L. McCreery, J. Electrochem. Soc., 2004, 151, B252-B259.

22 Y. A. Atmane, L. Sicard, A. Lamouri, J. Pinson, M. 1. Sicard, C. Masson, S. Nowak, P. Decorse, J.-Y. Piquemal and A. Galtayries, J. Phys. Chem. C, 2013, 117, 26000-26006.

23 K. Bell, P. Brooksby, M. Polson and A. Downard, Chem. Commun., 2014, 50, 13687-13690.

24 M. Hinge, M. Ceccato, P. Kingshott, F. Besenbacher, S. U. Pedersen and K. Daasbjerg, New J. Chem., 2009, 33, 2405-2408.

25 K. Brymora, J. Fouineau, A. Eddarir, F. Chau, N. Yaacoub, J.-M. Grenèche, J. Pinson, S. Ammar and F. Calvayrac, J. Nanopart. Res., 2015, 17, 438.

26 F. Lamberti, S. Agnoli, L. Brigo, G. Granozzi, M. Giomo and N. Elvassore, ACS Appl. Mater. Interfaces, 2013, 5, 1288712894.

27 M. Hinge, E. S. Gonçalves, S. U. Pedersen and K. Daasbjerg, Surf. Coat. Technol., 2010, 205, 820-827.

28 S. Mercier, F. Iozzelli, M. P. Bacos and P. Josso, in Materials Science Forum, 2004, vol. 461-464, pp. 949-956.

29 Y. S. Wang, S. Narasimhan, J. M. Larson and S. K. Schaefer, J. Mater. Eng. Perform., 1998, 7, 53-65.

$30 \mathrm{~S}$. H. Teoh, Engineering materials for biomedical applications, World scientific, 2004.

31 L. Shi, D. O. Northwood and Z. Cao, J. Mater. Sci., 1994, 29, 1233-1238.

32 Y. S. Al Jabbari, J. Adv. Prosthodont., 2014, 6, 138-145.

33 B. Bergman, A. Hugoson and C. O. Olsson, J. Oral Rehabil., 1995, 22, 595-599.

34 B. E. Pjetursson, W. C. Tan, K. Tan, U. Brägger, M. Zwahlen and N. P. Lang, Clin. Oral. Implants Res., 2008, 19, 131-141. 35 D. G. Castner and B. D. Ratner, Surf. Sci., 2002, 500, 28-60.
36 S. Taksali, J. N. Grauer and A. R. Vaccaro, Spine J., 2004, 4, S231-S238.

37 A. Hodgson, S. Kurz, S. Virtanen, V. Fervel, C.-O. Olsson and S. Mischler, Electrochim. Acta, 2004, 49, 2167-2178.

38 H. E. Placko, S. A. Brown and J. H. Payer, J. Biomed. Mater. Res., Part A, 1998, 39, 292-299.

39 Y. Liao, E. Hoffman, M. Wimmer, A. Fischer, J. Jacobs and L. Marks, Phys. Chem. Chem. Phys., 2013, 15, 746-756.

40 S. Hiromoto, E. Onodera, A. Chiba, K. Asami and T. Hanawa, Biomaterials, 2005, 26, 4912-4923.

41 A. Katerski, A. Mere, V. Kazlauskiene, J. Miskinis, A. Saar, L. Matisen, A. Kikas and M. Krunks, Thin Solid Films, 2008, 516, 7110-7115.

42 T. Kilner, R. Pilliar, G. Weatherly and C. Allibert, J. Biomed. Mater. Res., Part A, 1982, 16, 63-79.

43 J. Wilson, J. Walton and G. Beamson, J. Electron Spectrosc. Relat. Phenom., 2001, 121, 183-201.

44 T. E. Jacobson, Int. J. Prosthodont., 1989, 2, 163-172.

45 H. Shimizu, K. S. Kurtz, Y. Tachii and Y. Takahashi, J. Dent., 2006, 34, 117-122.

46 M. Rosso, A. Arafat, K. Schroën, M. Giesbers, C. S. Roper, R. Maboudian and H. Zuilhof, Langmuir, 2008, 24, 40074012.

47 M. Bojinov, G. Fabricius, T. Laitinen, T. Saario and G. Sundholm, Electrochim. Acta, 1998, 44, 247-261.

48 K. Boukerma, M. M. Chehimi, J. Pinson and C. Blomfield, Langmuir, 2003, 19, 6333-6335.

49 X. T. Le, G. Zeb, P. Jégou and T. Berthelot, Electrochim. Acta, 2012, 71, 66-72.

50 L. Mudford, R. Curtis and J. Walter, J. Dent., 1997, 25, 415421.

51 K. B. May, J. Fox, M. E. Razzoog and B. R. Lang, J. Prosthet. Dent., 1995, 73, 428-431.

52 C. Ohkubo, I. Watanabe, T. Hosoi and T. Okabe, J. Prosthet. Dent., 2000, 83, 50-57.

53 M. Bulbul and B. Kesim, J. Prosthet. Dent., 2010, 103, 303308.

54 S.-S. Kim, M.-S. Vang, H.-S. Yang, S.-W. Park and H.-P. Lim, J. Adv. Prosthodont., 2009, 1, 41-46.

55 R. A. Franking, E. C. Landis and R. J. Hamers, Langmuir, 2009, 25, 10676-10684. 